\title{
Competition between State Universities
}

\author{
Lisa Grazzini, ${ }^{*}$ Annalisa Luporini, ${ }^{\dagger}$ and Alessandro Petretto ${ }^{\ddagger}$
}

19 March 2010

\begin{abstract}
We analyse how state university competition to collect resources may affect both the quality of teaching and research. By considering a set-up where two state universities behave strategically, we model their interaction with potential students as a sequential noncooperative game. We show that different types of equilibrium may arise, depending on the mix of research and teaching activity supplied by each university, and the mix of low and high ability students attending each university. The most efficient equilibrium results in the creation of an élite institution attended only by high ability students. Low ability students are segregated in the other university, but obtain the same teaching quality level and pay the same tuition fees.
\end{abstract}

Keywords: University Competition, Research, Tuition Fees.

JEL Classification: H52; I22; I23.

\footnotetext{
*Department of Economics, University of Florence, Via delle Pandette 9, 50127 Florence, Italy. E-mail: lisa.grazzini@unifi.it

${ }^{\dagger}$ Department of Economics, University of Florence, Via delle Pandette 9, 50127 Florence, Italy. E-mail: annalisa.luporini@unifi.it

${ }^{\ddagger}$ Department of Economics, University of Florence, Via delle Pandette 9, 50127 Florence, Italy. E-mail: alessandro.petretto@unifi.it.

We are deeply grateful to Riccardo Martina and Raffaela Giordano for extremely helpful comments. We also wish to thank participants at ASSET 2009, SIEP 2009, SIE 2009, and NERI 2009 for fruitful discussions.
} 


\section{Introduction}

Notwithstanding researchers are part of it, the economic literature on education has traditionally ignored the competition for students and public funding among public universities (Boroah (1994), De Fraja and Iossa (2002), Johnes (2007), Gautier and Wauthy (2007)). Instead, there exist several theoretical and empirical papers on competition between private and public schools and universities (Epple and Romano (1998, 2008), Bailey et al. (2004), Bertola and Checchi (2003), Oliveira (2006)).

This paper aims to analyse how state university competition to collect resources may affect the quality of teaching and the level of research. In this respect, two main remarks are in order. First, as it was suggested by Rothschild and White (1995), universities compete for students because universities adopt a customer-input technology, i.e. students are at once inputs and customers of the educational process. More precisely, students are inputs needed to produce education, but they also provide funds to universities both by paying tuition fees, and by allowing universities to receive transfers from the government. Second, Cohn and Cooper (2004) stress the fact that universities are multi-product institutions that supply three types of output: teaching, research, and public services. Teaching has the aim to deliver knowledge both at undergraduate and postgraduate level. Research has, instead, the aim to create knowledge with externalities for all society. Research may be considered as complementary to teaching in case of postgraduate courses, while it is probably a substitute in case of undergraduate courses. Finally, universities produce a third output which can be thought of as a public service: for example, in Italy, as well as in many other countries, university diploma have a legal value.

To tackle such an issue, we consider a set-up where two state universities behave strategically. ${ }^{1}$ Their interaction with potential students is thus modelled as a sequential noncooperative game. Given a public funding mechanism, at the first stage, the universities choose their tuition fees and investments in teaching and research; at the second stage, students choose which university to attend depending on a benefit-cost comparison. Under the assumption of perfect mobility of students, the cost of attending one university only depends on tuition fees (for simplicity, other costs are assumed equal). The benefit derived from attending one university or the other, instead, depends on each student's own ability and on the quality of teaching which includes a peer group effect. Consequently also the average ability of students attending each university is relevant from an individual point of view (Epple and Romano (1998)). Prior to the first stage, the government determines the level of the public transfers to each university with the objective to maximise the level of research and the quality of teaching subject to an efficient use of financial resources.

By solving the model, we show that different types of equilibrium may arise, depending on the mix of research and teaching quality supplied by each university, and on the mix of low and high ability students attending each university. More precisely, each equilibrium is characterized from two points of view. On the one side, universities may choose to specialize only in research or teaching, or instead to supply both. On the other side, students with different ability allocate

\footnotetext{
${ }^{1}$ See Aghion et al. (2010) for an empirical analysis of the link among universities' autonomy, competition, and research performance. See also Veugelers and Van Der Ploeg (2008).
} 
between universities in different ways. Possible equilibria are the following: 1) an equilibrium where there is complete segregation, i.e. all high ability students attend one university, and all low ability students attend the other university; 2) an equilibrium where all high ability students attend one university, and low ability students attend either one or the other institution; 3) an equilibrium where all students attend one university, and the other institution only produces research. From a social point of view, we show that the first equilibrium is the most efficient. When compared to the second equilibrium, the first one allows to attain a higher teaching quality at the same public extra-research cost. When compared to the third equilibrium, the first one allows to reach the same teaching quality and research level at a lower public cost.

Our paper is related to two strands of economic literature which we try to combine in order to gather some new hints on university incentives. More specifically, we refer both to the literature on public university competition, and to the literature on capital tax competition with household mobility. As we stressed above, competition between public universities has received limited attention, even if some recent papers have tried to shed some light on such an issue. Del Rey (2001) uses a spatial competition model to analyse a game between two universities which provide both research and teaching, and use admission standards to control the average ability of enrolled students. Depending on preferences, technologies, and public policies, different types of symmetric equilibrium may arise: both universities admit only some of the applicants and provide research; both universities satisfy all students' demand and provide research; both are 'research only' universities. In a related paper, De Fraja and Iossa (2002) focus the attention on how students' mobility costs may affect the equilibrium configuration. In particular, if mobility costs are high, as in Del Rey (2001), the equilibrium is symmetric: both universities admit the same number of students, and research investments are the same. If mobility costs are sufficiently low, instead, the resulting equilibrium (provided it exists) is asymmetric, i.e. one university (the 'élite institution') admits the best students, and provides more research than the other. ${ }^{2}$ More recently, Kemnitz (2007) examines how different public funding schemes may affect competition among universities, and thus the quality of their teaching and research. Hubner (2009) extends the previous analyses by showing that the introduction of tuition fees can raise the quality of education, and the number of students when both central and local governments lack sufficient instruments to tax the high-skilled population.

Contrary to what happens with university competition, the literature on capital tax competition is quite large (for surveys see Wellish (2000), Hindriks and Myles (2006)). In this respect, a familiar result is that tax competition for perfectly mobile capital results in underprovision of local public goods when households are perfectly immobile. Such result, however, does not hold when households are allowed to be perfectly mobile. Fiscal externalities, which are at the basis of the result on local public good underprovision, disappear when households are mobile: each region/country internalizes the effects of its own policies on the welfare of nonresidents by taking the migration equilibrium into account. Accordingly, introducing mobility of households in the

\footnotetext{
${ }^{2}$ Optimal research and teaching decisions are also analysed by De Fraja and Valbonesi (2009) who however consider that in each local education market there is a single university that acts as a monopolist.
} 
standard capital tax competition model mitigates the downward pressure on local public goods provision (Wellish 2000, p.105).

The aim of the present paper is to combine these two strands of literature in order to analyse how students' mobility affects university competition on both tuition fees, and expenditure in research and teaching. Contrary to most of the existing literature on state university competition, we do not use a spatial competition model, but we use the methodological tools offered by the literature on capital tax competition. Further, in our paper, universities do not set admission standards, thus students are free to attend the university they prefer on the basis of a cost-benefit analysis. This scenario fits better the European set-up than the U.S. one, and is probably more suitable to describe undergraduate degrees.

The plan of the paper is as follows. Section 2 describes the model. Section 3 analyses students' university choice and characterizes three different type of stable equilibria that may arise. Section 4 examines how universities compete with respect to their choice of tuition fees and expenditure for research and teaching. Section 5 compares the outcomes of the three equilibria from a social point of view. Finally, section 6 contains some concluding remarks.

\section{The model}

Consider two universities denoted by $j, j=A, B$, operating in the same district, and differing with respect to quality of teaching, $q_{j}$, and level of research, $r_{j}$. Students have to choose which university to attend. Students differ with respect to their ability, $e^{i}$, which can be high, $e^{h}$, or low, $e^{l}$, with $e^{h}>e^{l}$. The preferences of each student, are represented by the following utility function

$$
U^{i}\left(q_{j}\right)-b_{j}, \quad i=h, l, \quad j=A, B,
$$

where $b_{j}$ denotes the per-student tuition fee paid to university $j$. We assume that high ability students derive a higher level of utility from any given level of $q_{j}$, i.e. $U^{h}\left(q_{j}\right)>U^{l}\left(q_{j}\right)$, and that university quality positively affects students' utility at a decreasing rate, $\frac{d U^{i}}{d q_{j}}>0, \frac{d^{2} U^{i}}{d\left(q_{j}\right)^{2}}<0$ with $\frac{d U^{h}}{d q_{j}}>\frac{d U^{l}}{d q_{j}}$. The exogenous total number of students is $N=\sum_{i=h, l} N^{i}$, where $N^{h}$ is the total number of high ability students, and $N^{l}$ the total number of low ability students with $N^{l} \geq N / 2$. We assume that all students attend one of the two universities and thus $N=n_{A}+n_{B}$, where $n_{j}$ denotes the total number of students attending university $j, j=A, B$. Further, $n_{j}^{i}, i=h, l$, denotes the total number of students belonging to each type and attending each university so that $n_{j}=\sum_{i=h, l} n_{j}^{i}, j=A, B$, and $N^{i}=\sum_{j=A, B} n_{j}^{i}, i=h, l$. Let us denote with $\bar{e}_{j}$ the average ability of students attending university $j$. Accordingly, the average ability of students attending university $j, j=A, B$, obtains as

$$
\bar{e}_{j}=\frac{\sum_{i=h, l} n_{j}^{i} e^{i}}{n_{j}}=\frac{n_{j}^{h}}{n_{j}} \Delta+e^{l},
$$

with $\Delta \equiv e^{h}-e^{l}$. 
Each university may receive two types of transfer from the government. Let $t_{j} \geq 0$ denote a per-student transfer to university $j$, and $\tau_{j} \geq 0$ denote a lump-sum transfer, $j=A, B$. Accordingly, the budget constraint of each university $j, j=A, B$, obtains as

$$
\left(t_{j}+b_{j}\right) n_{j}+\tau_{j}=T_{j}+R_{j}, \quad j=A, B
$$

where $T_{j} \geq 0$ and $R_{j} \geq 0$ represent expenditure on teaching and research by university $j, j=A, B$, respectively. Notice that universities are not constrained in the destination of the transfers. The sums thus received can be used either to finance teaching or research.

Each university produces teaching according to the following production function ${ }^{3}$

$$
q_{j}=\alpha \bar{e}_{j}+\beta \frac{T_{j}}{n_{j}}, \quad j=A, B, \text { with } \alpha>0, \quad \beta>0, \quad \text { and } q_{j}=0 \text { when } n_{j}=0 .
$$

Each university can improve the quality of its teaching by augmenting the average quality of its students and/or its teaching expenditure, for example by increasing its teacher/students ratio. $\alpha$ and $\beta$ measure how the peer group effect and per student teaching expenditure translate into teaching quality and are thus the same in both universities. The quality of teaching is independent of research. This means that we mostly refer to undergraduate courses.

Further, each university produces research according to the following production function with decreasing returns ${ }^{4}$

$$
r_{j}=R_{j}^{\gamma_{j}}, \quad j=A, B, \quad 0<\gamma_{j}<1,
$$

where $\gamma_{j}$ represents an index of efficiency of research activity specific to each university. Then, each university can improve the quality of its research by augmenting its expenditure on research activity, for example, by recruiting better researchers and by purchasing more sophisticated equipments (De Fraja and Iossa (2002)).

Finally, each university cares about both teaching and research and thus we assume the following objective functions

$$
W_{j}=\sum_{i=h, l} n_{j}^{i} q_{j}+r_{j}, \quad j=A, B,
$$

according to which, in the intent of the universities, there is perfect substitutability between total quality of teaching and research. ${ }^{5}$

The game is solved by backward induction. We first examine the students' decision on which university to attend and then the universities' decisions on tuition fees, on research and teaching expenditure.

\footnotetext{
${ }^{3}$ This is a common form for the teaching production function, see e.g. Del Rey (2001).

${ }^{4}$ See also Gautier and Wauthy (2007).

${ }^{5}$ In order to sum up the two components of the objective function, $q_{j}$ and $r_{j}$ indexes must be normalized. The same type of objective function is also used by Del Rey (2000) while de Fraja and Iossa (2002) assume that universities are interested in maximising their prestige which is formalized as a function of the number of students, the average ability of the student body, and research expenditure. More recently, De Fraja and Valbonesi (2008) suppose that universities are only interested in maximising their amount of research, so that teaching is not an end in itself, but a mean to fund research.
} 


\section{Students' university choice and characterization of stable equi- libria}

Consider the second stage of the game when students make their decisions. If both universities enrol students of a given type, at equilibrium those students must be indifferent with respect to which university to attend. This implies that the following arbitrage condition has to hold ${ }^{6}$

$$
U^{i}\left(q_{A}\right)-b_{A}=U^{i}\left(q_{B}\right)-b_{B}, \quad i=h, l .
$$

Recall that the quality of teaching depends on per-student expenditure and on average students' ability. It is consequently affected both by the number of students and by the proportion of high ability individuals. By using (4), and (3) into (1), the effect of the number of students on individual utility obtains as

$$
\frac{\partial U^{i}}{\partial n_{j}^{i}}=\frac{d U^{i}}{d q_{j}} \frac{\partial q_{j}}{\partial n_{j}^{i}}, \quad i=h, l ; \quad j=A, B
$$

Accordingly, $\operatorname{sign} \frac{\partial U^{i}}{\partial n_{j}^{i}}=\operatorname{sign} \frac{\partial q_{j}}{\partial n_{j}^{i}}$, because $\frac{d U^{i}}{d q_{j}}>0$ by assumption. Further, by using (2) and (3) into (4), the effect of the number of students on teaching quality obtains as

$$
\frac{\partial q_{j}}{\partial n_{j}^{i}}=\alpha \frac{\partial \bar{e}_{j}}{\partial n_{j}^{i}}+\beta \frac{\partial\left(T_{j} / n_{j}\right)}{\partial n_{j}^{i}}, \quad i=h, l, \quad j=A, B
$$

when $n_{j}>0$. More specifically, for high ability students, $i=h$, equation (9) rewrites as

$$
\frac{\partial q_{j}}{\partial n_{j}^{h}}=\frac{1}{n_{j}^{2}}\left[\alpha \Delta n_{j}^{l}+\beta\left(R_{j}-\tau_{j}\right)\right], \quad j=A, B,
$$

and for low ability students, $i=l$, equation (9) rewrites as

$$
\frac{\partial q_{j}}{\partial n_{j}^{l}}=\frac{1}{n_{j}^{2}}\left[-\alpha \Delta n_{j}^{h}+\beta\left(R_{j}-\tau_{j}\right)\right], \quad j=A, B .
$$

Notice that the effect of $n^{i}$ on quality depends on two terms. The first one represents the direct effect of an additional student on average quality and is positive (negative) for high (low) ability students. The second one represents the indirect effect that an additional student has on perstudent teaching expenditure and is positive (negative) if research expenditure is higher (lower) than the lump-sum transfer. The reason is that the excess of research expenditure over the lump sum transfer is financed by the fees paid by a higher (lower) number of students.

We are now in a position to determine the sign of $\frac{\partial q_{j}}{\partial n_{j}^{i}}, i=h, l$.

Lemma 1: i) For $n_{j}^{h}>0$, $\frac{\partial q_{j}}{\partial n_{j}^{h}} \gtrless 0$ iff $R_{j}-\tau_{j} \gtrless-\frac{\alpha}{\beta} \Delta n_{j}^{l}$, with $n_{j}^{l} \geq 0$.

$$
\text { ii) For } n_{j}^{l}>0 \frac{\partial q_{j}}{\partial n_{j}^{l}} \gtrless 0 \text { iff } R_{j}-\tau_{j} \gtrless \frac{\alpha}{\beta} \Delta n_{j}^{h} \text {, with } n_{j}^{h} \geq 0 \text {. }
$$

\footnotetext{
${ }^{6}$ This condition is quite familiar in the literature dealing with tax competition with household mobility. See for instance Wellish (2000, p.111).
} 
Notice that at $n_{j}^{i}=0$ it is

$$
\left.\frac{\partial q_{j}}{\partial n_{j}^{i}}\right|_{n_{j}=0}=\alpha e_{j}^{i}+\beta\left(t_{j}+b_{j}+\tau_{j}-R_{j}\right)>0, \quad j=A, B, i=h, l,
$$

because $t_{j}+b_{j}+\tau_{j}-R_{j}=T_{j} \geq 0$.

The sign of $\frac{\partial q_{j}}{\partial n_{i}^{i}}, i=h, l, j=A, B$, is crucial in determining the type of locally stable equilibrium which occurs at the students' subgame. An interesting point is that, for each university, the effect of the number of high (low) ability students on the quality of teaching depends on the number of low (high) ability students.

In this respect, we can state the following

Proposition 1 There does not exist a stable equilibrium where high ability students attend both university $A$ and $B$.

Proof. We divide the proof in two cases, showing that there cannot exist: i) a stable equilibrium where all $l$ students attend university $A$ and $h$ students attend either university $A$ or university $B$; ii) a stable equilibrium where both $l$ and $h$ students attend either university $A$ or university $B$.

i) Suppose, contrary to proposition 1 , that there exists a stable equilibrium where all $l$ students choose university $A$ and $h$ students attend both university $A$ and $B$. Stability requires that $\frac{\partial q_{j}}{\partial n_{j}^{h}}<0$, $j=A, B$, and $\frac{\partial q_{A}}{\partial n_{A}^{l}}>0$. Let us consider university $A$. In order to have $\frac{\partial q_{A}}{\partial n_{A}^{h}}<0$, it must be that $\tau_{A}-R_{A}>\frac{\alpha}{\beta} \Delta N^{l}>0$, from Lemma 1. But, in order to have $\frac{\partial q_{A}}{\partial n_{A}^{l}}>0$, Lemma 1 prescribes that $R_{A}-\tau_{A}>\frac{\alpha}{\beta} \Delta n_{A}^{h}>0$, which contradicts the previous condition.

ii) In order to have a stable equilibrium where students of both types $l$ and $h$ attend both university $A$ and $B$, the following conditions should be satisfied:

$$
\begin{aligned}
& U^{h}\left(\alpha\left(e^{l}+\frac{\Delta n_{A}^{h}}{n_{A}^{h}+n_{A}^{l}}\right)+\beta\left(t_{A}+b_{A}+\frac{\tau_{A}-R_{A}}{n_{A}^{h}+n_{A}^{l}}\right)\right)-b_{A}= \\
= & U^{h}\left(\alpha\left(e^{l}+\frac{\Delta n_{B}^{h}}{n_{B}^{h}+n_{B}^{l}}\right)+\beta\left(t_{B}+b_{B}+\frac{\tau_{B}-R_{B}}{n_{B}^{h}+n_{B}^{l}}\right)\right)-b_{B}, \\
& U^{l}\left(\alpha\left(e^{l}+\frac{\Delta n_{A}^{h}}{n_{A}^{h}+n_{A}^{l}}\right)+\beta\left(t_{A}+b_{A}+\frac{\tau_{A}-R_{A}}{n_{A}^{h}+n_{A}^{l}}\right)\right)-b_{A}= \\
= & U^{l}\left(\alpha\left(e^{l}+\frac{\Delta n_{B}^{h}}{n_{B}^{h}+n_{B}^{l}}\right)+\beta\left(t_{B}+b_{B}+\frac{\tau_{B}-R_{B}}{n_{B}^{h}+n_{B}^{l}}\right)\right)-b_{B} .
\end{aligned}
$$

But, given the assumption that $\frac{\partial U^{h}}{\partial q_{j}}>\frac{\partial U^{l}}{\partial q_{j}}$, these equations cannot be simultaneously satisfied. $\square$

The reason why a situation where $h$ students are found in both universities cannot represent a stable equilibrium is that an additional $h$ student tends to improve the quality of the university he enrols in. More precisely, we know from from (10) that quality is increased unless i) the university is attended only by $h$ students and ii) the lump sum transfer exceeds research expenditure. This, however, could be the case for one university but not for the other. Consequently, it is profitable 
for $h$ students to concentrate in the same university. We are then left with the following stable equilibria: ${ }^{7}$

Equilibrium I: all $h$ students attend university $A$ and all $l$ students attend university $B$.

Equilibrium II: all $h$ students attend university $A$ and $l$ students attend either university $A$ or university $B$.

Equilibrium III: all students attend university $A$. University $B$ only produces research.

\section{Equilibrium $I$}

In this equilibrium a process of perfect segregation takes place. Formally, for all $h$ students to choose university $A$ and all $l$ students to choose university $B$, the following conditions must be satisfied: ${ }^{8}$

$$
U^{h}\left(\alpha e^{h}+\beta\left(t_{A}+b_{A}+\frac{\tau_{A}-R_{A}}{N^{h}}\right)\right)-b_{A} \geq U^{h}\left(\alpha e^{l}+\beta\left(t_{B}+b_{B}+\frac{\tau_{B}-R_{B}}{N^{l}}\right)\right)-b_{B}
$$

and

$$
U^{l}\left(\alpha e^{l}+\beta\left(t_{B}+b_{B}+\frac{\tau_{B}-R_{B}}{N^{l}}\right)\right)-b_{B} \geq U^{l}\left(\alpha e^{h}+\beta\left(t_{A}+b_{A}+\frac{\tau_{A}-R_{A}}{N^{h}}\right)\right)-b_{A} .
$$

In order for this equilibrium to be stable it must be the case that the effect of the number of students on quality is positive, i.e. $\frac{\partial q_{j}}{\partial n_{j}^{i}}>0, j=A, B, i=l, h$. Considering that the difference between $R_{j}$ and $\tau_{j}$ if positive (negative) subtracts (contributes) resources to teaching, (10) implies that for high ability students the indirect effect through teaching expenditure must be either positive or, if negative, lower than the direct effect through the level of average ability. For low ability students instead (11) implies that the indirect effect through teaching expenditure must be higher than the direct effect through the level of average ability. By Lemma 1, this equilibrium arises if and only if $R_{j}>\tau_{j}, j=A, B$, i.e. if the lump-sum transfer is not high enough to cover research expenditure. In this case an increase in the number of students raises per-student teaching expenditure as it reduces the per-student amount of resources substracted from teaching activity. Consequently the quality of its teaching increases.

\section{Equilibrium II}

In this equilibrium university $A$ is attended by both types of students, while university $B$ is attended only by low ability students. Formally, for all $h$ students to choose university $A$ and $l$ students to attend either university $A$ or $B$, the following conditions must be satisfied:

$$
\begin{gathered}
U^{h}\left(\alpha\left(e^{l}+\frac{\Delta N^{h}}{N^{h}+n_{A}^{l}}\right)+\beta\left(t_{A}+b_{A}+\frac{\tau_{A}-R_{A}}{N^{h}+n_{A}^{l}}\right)\right)-b_{A}> \\
U^{h}\left(\alpha e^{l}+\beta\left(t_{B}+b_{B}+\frac{\tau_{B}-R_{B}}{n_{B}^{l}}\right)\right)-b_{B},
\end{gathered}
$$

\footnotetext{
${ }^{7}$ More precisely, there are three types of equilibria. For each type, there actually exist two symmetric equilibria. The second one can be obtained by simply exchanging the subscript $A$ for $B$ and viceversa.

${ }^{8}$ We assume that universities fix tuition fees without taking into account the marginal effect of a student movement on teaching quality. Given that $N$ is large, such effect is negligible.
} 
and

$$
\begin{gathered}
U^{l}\left(\alpha e^{l}+\beta\left(t_{B}+b_{B}+\frac{\tau_{B}-R_{B}}{n_{B}^{l}}\right)\right)-b_{B}= \\
=U^{l}\left(\alpha\left(e^{l}+\frac{\Delta N^{h}}{N^{h}+n_{A}^{l}}\right)+\beta\left(t_{A}+b_{A}+\frac{\tau_{A}-R_{A}}{N^{h}+n_{A}^{l}}\right)\right)-b_{A} .
\end{gathered}
$$

In order for this equilibrium to be stable it must be the case that $\frac{\partial q_{A}}{\partial n_{A}^{h}}>0$, and $\frac{\partial q_{j}}{\partial n_{j}^{l}}<0, j=A, B$. This means that quality increases with high ability students and decreases with low ability ones for both universities. By Lemma 1, this implies

$$
-\frac{\alpha}{\beta} \Delta N^{h}<\tau_{A}-R_{A}<\frac{\alpha}{\beta} \Delta n_{A}^{l},
$$

and

$$
0<\tau_{B}-R_{B}<\frac{\alpha}{\beta} \Delta n_{B}^{l}
$$

For university $B$, the lump sum transfer $\tau_{B}$ must exceed research expenditure. Funds in excess can thus be used to improve teaching quality. Otherwise quality would be too low because there are no high ability students. As a consequence of the high lump sum transfer, university $B$ has no need to attract too many $(l)$ students. For university $A, \tau_{A}$ may exceed or be lower than $R_{A}$. In university $A$ there is an incentive to attract students in order to finance teaching. Low ability students act mainly as a tool to finance the high quality of teaching of university $A$ via their tuition fees.

Further, for low ability students, we derive the impact of universities' decisions on their location, by stating the following

Lemma 2. At equilibrium II, for low ability students it is $\frac{d n_{j}^{l}}{d b_{j}} \leq 0$, and $\frac{d n_{j}^{l}}{d R_{j}}<0$.

Proof. By totally differentiating (7), the following equation obtains

$$
\begin{gathered}
\frac{d U_{A}^{i}}{d q_{A}} \sum_{i=h, l} \frac{\partial q_{A}}{\partial n_{A}^{i}} d n_{A}^{i}+\frac{d U_{A}^{i}}{d q_{A}} \frac{\partial q_{A}}{\partial R_{A}} d R_{A}+\frac{d U_{A}^{i}}{d q_{A}} \frac{\partial q_{A}}{\partial b_{A}} d b_{A}-d b_{A}+ \\
-\frac{d U_{B}^{i}}{d q_{B}} \sum_{i=h, l} \frac{\partial q_{B}}{\partial n_{B}^{i}} d n_{B}^{i}-\frac{d U_{B}^{i}}{d q_{B}} \frac{\partial q_{B}}{\partial R_{B}} d R_{B}-\frac{d U_{B}^{i}}{d q_{B}} \frac{\partial q_{B}}{\partial b_{B}} d b_{B}+d b_{B}=0 .
\end{gathered}
$$

By using the market clearing condition for low ability students, $d n_{B}^{l}=-d n_{A}^{l}$ and $d n_{B}^{h}=d n_{A}^{h}=0$ into (18), it follows that

$$
\begin{array}{cc}
\frac{d n_{j}^{l}}{d b_{j}}=\frac{1-\beta \frac{\partial U_{j}^{l}}{\partial q_{j}}}{J^{l}}, \quad j=A, B, \\
\frac{d n_{j}^{l}}{d R_{j}}=\frac{\frac{\beta}{n_{j}} \frac{\partial U_{j}^{l}}{\partial q_{j}}}{J^{l}}, \quad j=A, B,
\end{array}
$$

where

$$
J^{l}=\sum_{j=A, B} \frac{\partial U_{j}^{l}}{\partial q_{j}} \frac{\partial q_{j}}{\partial n_{j}^{l}}, \quad j=A, B .
$$

Given that $\frac{\partial q_{j}}{\partial n_{j}^{l}}<0, J^{l}<0$ in $(21)$ because $\frac{\partial U_{j}^{l}}{\partial q_{j}}>0$ by assumption. Then $\frac{d n_{j}^{l}}{d R_{j}}<0$ follows immediately from (20). Moreover, from (19) it follows that $\frac{\partial U_{j}^{l}}{\partial q_{j}} \gtreqless \frac{1}{\beta} \Longleftrightarrow \frac{d n_{j}^{l}}{d b_{j}} \gtreqless 0$. Note however 
that it cannot be $\frac{\partial U_{j}^{l}}{\partial q_{j}}>\frac{1}{\beta}$ at equilibrium because this would imply that students' utility could be increased by increasing $b_{j}$ (which would obviously improve also universities' welfare). Hence $\frac{d n_{j}^{l}}{d b_{j}} \leq 0$.

Lemma 2 shows that the number of low ability students attending each university depends negatively on $b_{j}$, and $R_{j}$. In particular, for $b_{j}$, such an effect is higher the lower the value of $\beta$, i.e. a low impact of per-student teaching expenditure on quality. With a low $\beta$ it is quite likely that a large number of low skill students decide to move away from the university that raises the tuition fee. For $R_{j}$, instead, the effect is higher the higher the value of $\beta$. On the contrary, the location choice of high ability students is not affected by marginal changes in $b_{j}$ and $R_{j}$, because the corresponding locally stable equilibrium is a corner one.

\section{Equilibrium III}

In this equilibrium, university $B$ is fully specialized, i.e. there are no students and only research is carried on. University $A$, on the contrary, produces both teaching and research. Formally, for all students to choose university $A$, so that university $B$ only produces research, the following conditions must be satisfied:

$$
U^{h}\left(\alpha\left(e^{l}+\frac{\Delta N^{h}}{N}\right)+\beta\left(t_{A}+b_{A}+\frac{\tau_{A}-R_{A}}{N}\right)\right)-b_{A} \geq U^{h}(0)=0,
$$

and

$$
U^{l}\left(\alpha\left(e^{l}+\frac{\Delta N^{h}}{N}\right)+\beta\left(t_{A}+b_{A}+\frac{\tau_{A}-R_{A}}{N}\right)\right)-b_{A} \geq U^{l}(0)=0
$$

where $b_{B}=0$. In order for this equilibrium to be stable it must be the case that $\frac{\partial q_{A}}{\partial n_{A}^{i}}>0, i=h, l$. By Lemma 1, this implies that $R_{A}-\tau_{A}>\frac{\alpha}{\beta} \Delta N^{h}$. Notice that for $n_{B}=0$, the following conditions must be satisfied, $\frac{\partial q_{B}}{\partial n_{B}^{i}}>0$ and $R_{B}=\tau_{B}$. In words, this means that equilibrium III may arise if university $A$ 's investment in research, $R_{A}$, is greater than the transfer received by the government to finance research, $\tau_{A}$, and the effect of an increase in the number of low ability students on university $A$ 's investment in teaching is greater than the effect on university $A$ 's average ability of students. University $B$ only produces research, and thus the government only provides a lump-sum transfer which is entirely spent on research.

Further, at equilibrium III, the location choices of both high and low ability students are not affected by marginal changes in universities' decisions.

\section{Universities' competition: Research expenditure and tuition fees}

At the first stage of the game, each university solves its maximisation problem in accordance with the type of equilibrium arising at the second stage. In particular each university behaves à la Nash with respect to its competitor but is a Stackelberg leader with respect to students. This means that each university decides tuition fees $b_{j}$, and research expenditure $R_{j}$ taking into account the reaction 
of students, i.e. their subsequent location decisions. Starting from each equilibrium of the second stage, we then solve the first stage considering that the objective function (6) must incorporate the corresponding equilibrium.

\subsection{Equilibrium I}

At equilibrium I of the second stage, where the students' location decisions are such thatM $n_{A}=$ $N^{h}, n_{B}=N^{l}$, the universities' objective functions (6) take the following form

$$
W_{A}=N^{h} \alpha e^{h}+\beta\left[\left(t_{A}+b_{A}\right) N^{h}+\left(\tau_{A}-R_{A}\right)\right]+R_{A}^{\gamma_{A}},
$$

and

$$
W_{B}=N^{l} \alpha e^{l}+\beta\left[\left(t_{B}+b_{B}\right) N^{l}+\left(\tau_{B}-R_{B}\right)\right]+R_{B}^{\gamma_{B}} .
$$

Accordingly, the first-order conditions w.r.t. $R_{j}, j=A, B$, are as follows

$$
\partial W_{j} / \partial R_{j}=\gamma_{j} R_{j}^{\gamma_{j-1}}-\beta=0, \quad j=A, B .
$$

As far as the tuition fees, are concerned, we have that both universities pay-offs are monotonic increasing functions of $b_{j}, j=A, B$ :

$$
\begin{aligned}
& \partial W_{A} / \partial b_{A}=\beta N^{h}>0, \\
& \partial W_{B} / \partial b_{B}=\beta N^{l}>0 .
\end{aligned}
$$

\subsubsection{Optimal research expenditure}

From (24), the optimal level of research expenditure, $R_{j}^{I}$, obtains as

$$
R_{j}^{I}=\left(\frac{\beta}{\gamma_{j}}\right)^{\frac{1}{\gamma_{j}-1}}, \quad j=A, B,
$$

and thus, the optimal level of research is as follows

$$
r_{j}^{I}=\left(\frac{\beta}{\gamma_{j}}\right)^{\frac{\gamma_{j}}{\gamma_{j}-1}}, \quad j=A, B .
$$

The optimal level of research is given by two technological elements $\beta$ and $\gamma_{j}$. The first represents the impact of per-student teaching expenditure on the quality of teaching (efficacy of teaching expenditure), and the second one is the coefficient transforming expenditure in effective research activity (efficacy of research expenditure). Given that $\gamma_{j}<1, r_{j}^{I}$ is increasing in $\gamma_{j}$ and decreasing in $\beta$. The higher the efficacy of research expenditure, the higher is the optimal level of research. The higher is the efficacy of teaching, on the contrary, the lower is the amount of research expenditure and consequently the level of research. Recall that in equilibrium I, $R_{j}>\tau_{j}, j=A, B$, i.e. tuition fees are needed to finance research. When teaching expenditure is highly efficient, relatively more resources are invested in teaching and consequently the sum available to finance research is reduced.

$R_{j}>\tau_{j}$ also implies that expenditure on research is independent of the lump sum transfer by the central government as well as of the per-student transfer because a small increase in $\tau_{j}$ or $t_{j}$ has no effect on the level of research, i.e. $\frac{\partial R_{j}^{I}}{\partial \tau_{j}}=0$, and $\frac{\partial R_{j}^{I}}{\partial t_{j}}=0$. 


\subsubsection{Optimal per student tuition fee}

Given (25), each university chooses the highest possible value of $b_{j}, j=A, B$. Such values result from the solution to the system of equations (12) and (13), characterizing equilibrium I, when they hold as equalities. In this respect, we can then state the following

Proposition 2 In Equilibrium $I, b_{A}^{I}=b_{B}^{I}=b^{I}$ and $q_{A}^{I}=q_{B}^{I}=q^{I}$.

Proof. Given that each university wants to keep tuition fees as high as possible (from (25)), the values of $b_{j}^{I}, j=A, B$ result from the solution to the system formed by conditions (12) and (13) holding as equalities, the following must hold:

$$
\begin{aligned}
& U^{h}\left(\alpha e^{h}+\beta\left(t_{A}+b_{A}+\frac{\tau_{A}-R_{A}}{N^{h}}\right)\right)-U^{h}\left(\alpha e^{l}+\beta\left(t_{B}+b_{B}+\frac{\tau_{B}-R_{B}}{N^{l}}\right)\right)=b_{A}^{I}-b_{B}^{I}, \\
& U^{l}\left(\alpha e^{h}+\beta\left(t_{A}+b_{A}+\frac{\tau_{A}-R_{A}}{N^{h}}\right)\right)-U^{l}\left(\alpha e^{l}+\beta\left(t_{B}+b_{B}+\frac{\tau_{B}-R_{B}}{N^{l}}\right)\right)=b_{A}^{I}-b_{B}^{I} .
\end{aligned}
$$

Given the assumption that $\frac{d U^{h}}{d q_{j}}>\frac{d U^{l}}{d q_{j}}$ the above system of equations has either no solution or the unique solution $b_{A}^{I}=b_{B}^{I}=b^{I}$. This implies that $q_{A}^{I}=q_{B}^{I}=q^{I}$.

This proposition shows that the quality of teaching is the same in both universities where the same tuition fee is charged. Low ability students, even if segregated, are not penalized in terms of quality of teaching and pay exactly the same as high ability ones. Corollary 1 shows that university $B$ is compensated for the lower quality of its students. The government must give relatively higher per-student and lump sum transfers to university $B,{ }^{9}$ and the difference in the transfers to universities $B$ and $A$ is positively related to the difference in students' ability.

Corollary 1: For Equilibrium I to exist, $t_{B}-t_{A}+\frac{R_{A}-\tau_{A}}{N^{h}}-\frac{R_{B}-\tau_{B}}{N^{l}}=\frac{\alpha}{\beta} \Delta>0$, where $R_{j}-\tau_{j}>0$, $j=A, B$.

Proof. Follows immediately from proposition 2 .

Proposition 2 shows that segregation takes place notwithstanding both universities charge equal tuition fees. Corollary 1 implies that if both $t_{B}$ and $t_{A}$ increase (decrease) by the same amount, $b_{A}^{I}$ and $b_{B}^{I}$ must decrease (increase), remaining however always equal. A variation in $t_{B}$ and/or $t_{A}$ can be also compensated by changes in $\tau_{A}$ and/or $\tau_{B}$. In any case $b^{I}$ will vary in the opposite direction.

Proposition 2 implies that the equilibrium values of teaching quality, in the L.H.S. of (27) and (28), are the same. Moreover, it imposes $b_{A}^{I}=b_{B}^{I}=b^{I}$, but it does not impose any constraint on the level of the fee. As a consequence, considering that for any $q_{j}, U^{h}\left(q_{j}\right)>U^{l}\left(q_{j}\right)$ by assumption, the value of $b^{I}$ is found from the solution to

$$
U^{l}\left(\alpha e^{l}+\beta\left(t_{B}+b^{I}+\frac{\tau_{B}-R_{B}}{N^{l}}\right)\right)-b^{I}=0 .
$$

\footnotetext{
${ }^{9}$ Recall however that $\tau_{B}$ must not exceed $R_{B}$.
} 
Thus, the utility of low ability students is zero while the utility of high ability students is positive because $\frac{d U^{h}}{d q_{j}}>\frac{d U^{l}}{d q_{j}}$. For university $B$, equation (29) shows that $t_{B}$ and $b^{I}$ are complements. A higher level of $t_{B}$ (and the consequent increase in $t_{A}$ implied by Corollary 1 ) in fact enables the universities to raise $b^{I}$ and, consequently, to further raise teaching quality. An increase in $t_{A}$, instead, has no effect on the level of the tuition fee, $b^{I}$.

\subsection{Equilibrium II}

At equilibrium II of the second stage, where the students' location decisions are such that $n_{A}=$ $N^{h}+n_{A}^{l}$ and $n_{B}=n_{B}^{l}$, university $A$ solves the following maximisation problem

$$
\begin{array}{cc}
\max _{b_{A}, R_{A}} & W_{A}=\left(N^{h}+n_{A}^{l}\right) q_{A}+r_{A} \\
\text { s.t. } & q_{A}=\alpha \bar{e}_{A}+\beta \frac{T_{A}}{n_{A}}, \\
& r_{A}=R_{A}^{\gamma_{A}}, \\
& \left(t_{A}+b_{A}\right)\left(N^{h}+n_{A}^{l}\right)+\tau_{A}=T_{A}+R_{A},
\end{array}
$$

and university $B$ solves

$$
\begin{array}{cc}
\max _{b_{B}, R_{B}} & W_{B}=n_{B}^{l} q_{B}+r_{B} \\
\text { s.t. } & q_{B}=\alpha \bar{e}_{B}+\beta \frac{T_{B}}{n_{B}^{l}}, \\
& r_{B}=R_{B}^{\gamma_{B}}, \\
& \left(t_{B}+b_{B}\right) n_{B}^{l}+\tau_{B}=T_{B}+R_{B} .
\end{array}
$$

Accordingly, the first-order conditions of these two problems are

$$
R_{A}: \quad \alpha \frac{\partial n_{A}^{l}}{\partial R_{A}} e^{l}+\beta\left[\left(t_{A}+b_{A}\right) \frac{\partial n_{A}^{l}}{\partial R_{A}}-1\right]+\gamma_{A} R_{A}^{\gamma_{A}-1}=0
$$

and

$$
b_{A}: \quad \alpha \frac{\partial n_{A}^{l}}{\partial b_{A}} e^{l}+\beta\left[\left(t_{A}+b_{A}\right) \frac{\partial n_{A}^{l}}{\partial b_{A}}+\left(N^{h}+n_{A}^{l}\right)\right]=0,
$$

for University $A$, and

$$
R_{B}: \quad \alpha \frac{\partial n_{B}^{l}}{\partial R_{B}} e^{l}+\beta\left[\left(t_{B}+b_{B}\right) \frac{\partial n_{B}^{l}}{\partial R_{B}}-1\right]+\gamma_{B} R_{B}^{\gamma_{B}-1}=0,
$$

and

$$
\left.b_{B}: \quad \alpha \frac{\partial n_{B}^{l}}{\partial b_{B}} e^{l}+\beta\left[\left(t_{B}+b_{B}\right) \frac{\partial n_{B}^{l}}{\partial b_{B}}+n_{B}^{l}\right)\right]=0,
$$

for university $B$.

\subsubsection{Optimal research expenditure}

Substituting (31) in (30) and (33) in (32), the optimal level of research expenditure $R_{j}^{I I}, j=A, B$, is the solution to

$$
\gamma_{j} R_{j}^{\gamma_{j}-1}-\beta\left(1+n_{j} \frac{\frac{\partial n_{j}^{l}}{\partial R_{j}}}{\frac{\partial n_{j}^{l}}{\partial b_{j}}}\right)=0,
$$


then

$$
R_{j}^{I I}=\left[\frac{\beta}{\gamma_{j}}\left(1-\frac{\frac{\partial n_{j}^{l}}{\partial R_{j}}}{D_{j}}\right)\right]^{\frac{1}{\gamma_{j}-1}}=\left[\frac{\beta}{\gamma_{j}}\left(1+\Omega_{j}\right)\right]^{\frac{1}{\gamma_{j}-1}}
$$

and thus the optimal level of research obtains as

$$
r_{j}^{I I}=\left[\frac{\beta}{\gamma_{j}}\left(1+\Omega_{j}\right)\right]^{\frac{\gamma_{j}}{\gamma_{j}-1}}
$$

where

$$
D_{j} \equiv-\frac{\frac{\partial n_{j}^{l}}{\partial b_{j}}}{n_{j}}>0
$$

and

$$
\Omega_{j} \equiv-\frac{\frac{\partial n_{j}^{l}}{\partial R_{j}}}{D_{j}}>0
$$

$D_{j}$ is positive because $\frac{\partial n_{j}^{l}}{\partial b_{j}}<0$ from Lemma 2. Thus, considering that $\frac{\partial n_{j}^{l}}{\partial R_{j}}<0$, it follows that $\Omega_{j}$ is positive too. Notice that $D_{j}$ is an index of tuition fee competition, because it measures the semi-elasticity of students with respect to the fee, i.e. the percentage of low ability students outflight due to an increase in the fee. Further, $\Omega_{j}$ is an index of the low ability students outflight due to an increase in expenditure on research, relatively to the index of tuition fee competition $D_{j}$. If one university increases its expenditure in research, low ability students tend to leave it because expenditure in teaching is reduced.

While in Equilibrium I, $r_{j}^{I}$ was determined by technological parameters, now $r_{j}^{I I}$ results from the product of a 'technological factor' $\left(\frac{\beta}{\gamma_{j}}\right)^{\frac{\gamma_{j}}{\gamma_{j}-1}}$ and a 'students' response factor' $\left(1+\Omega_{j}\right)^{\frac{\gamma_{j}}{\gamma_{j}-1}}$. When $\Omega_{j}$ is low, $r_{j}^{I I}$ tends to be determined only by technological parameters as in Equilibrium I. When $\Omega_{j}$ increases, $r_{j}^{I I}$ decreases. Observe that, given $\left(1+\Omega_{j}\right)^{\frac{\gamma_{j}}{\gamma_{j}-1}}<1$, research is lower in equilibrium II than in equilibrium I, i.e. $r_{j}^{I}>r_{j}^{I I}$. In university $B$, research expenditure is now completely covered by the lump sum transfer. ${ }^{10}$ In university $A$, instead, $\tau_{A}$ can be either lower or higher than $R_{A}^{I I}$. In the first case, students contribute to financing both teaching and research.

As far as the relation between $R_{A}^{I I}$ and $R_{B}^{I I}$ is concerned, notice that the relation between $\Omega_{A}$ and $\Omega_{B}$ depends on the relative quality of teaching. $\Omega_{j}$ can be re-written as

$$
\Omega_{j}=\frac{\frac{d U_{j}^{l}}{d q_{j}}}{1 / \beta-\frac{d U_{j}^{l}}{d q_{j}}}
$$

with $\frac{d U_{j}^{l}}{d q_{j}}<1 / \beta$ from Lemma 2. Since $U\left(\right.$.) is concave, if $q_{A} \gtreqless q_{B}$, then $\Omega_{A} \lesseqgtr \Omega_{B}$, and thus $R_{A}^{I I} \gtreqless R_{B}^{I I}$, unless $\gamma_{A}$ is much lower than $\gamma_{B}$.

\footnotetext{
${ }^{10}$ Recalling that in equilibrium I, $\tau_{B}<R_{B}$, this implies that the lump sum transfer $\tau_{B}$ needed to substain equilibrium II is higher than that of equilibrium I.
} 


\subsubsection{Optimal per student tuition fee}

Before determining the optimal levels of the tuition fees from the first order conditions, we can refer to the conditions (14) and (15) in order to state the following

Proposition 3 In equilibrium $I I, b_{A}^{I I}>b_{B}^{I I}$ and $q_{A}^{I I}>q_{B}^{I I}$.

Proof. (i) It cannot be $b_{A}^{I I}=b_{B}^{I I}$, because this implies $q_{A}^{I I}>q_{B}^{I I}$ from (14), but $q_{A}^{I I}=q_{B}^{I I}$ from (15). (ii) It cannot be $b_{A}^{I I}<b_{B}^{I I}$, because this implies that

$$
\begin{gathered}
b_{B}-b_{A}> \\
U^{h}\left(\alpha e^{l}+\beta\left(t_{B}+b_{B}+\frac{\tau_{B}-R_{B}}{n_{B}^{l}}\right)\right)-U^{h}\left(\alpha\left(e^{l}+\frac{\Delta N^{h}}{N^{h}+n_{A}^{l}}\right)+\beta\left(t_{A}+b_{A}+\frac{\tau_{A}-R_{A}}{N^{h}+n_{A}^{l}}\right)\right),
\end{gathered}
$$

from (14), and

$$
\begin{gathered}
b_{B}-b_{A}= \\
=U^{l}\left(\alpha e^{l}+\beta\left(t_{B}+b_{B}+\frac{\tau_{B}-R_{B}}{n_{B}^{l}}\right)\right)-U^{l}\left(\alpha\left(e^{l}+\frac{\Delta N^{h}}{N^{h}+n_{A}^{l}}\right)+\beta\left(t_{A}+b_{A}+\frac{\tau_{A}-R_{A}}{N^{h}+n_{A}^{l}}\right)\right),
\end{gathered}
$$

from (15). These conditions contradict each other because of the assumption $\frac{d U^{h}}{d q_{j}}>\frac{d U^{l}}{d q_{j}}$.

The optimal level of the tuition fee is obtained by solving (31) and (33):

$$
b_{A}^{I I}=-\frac{\alpha}{\beta} e^{l}-\frac{N^{h}+n_{A}^{l}}{\frac{\partial n_{A}^{l}}{\partial b_{A}}}-t_{A}=-\frac{\alpha}{\beta} e^{l}+\frac{1}{D_{A}}-t_{A},
$$

where $D_{A} \equiv-\frac{\frac{\partial n_{A}^{l}}{\partial b_{A}}}{N^{h}+n_{A}^{l}}$, and

$$
b_{B}^{I I}=-\frac{\alpha}{\beta} e^{l}-\frac{n_{B}^{l}}{\frac{\partial n_{B}^{l}}{\partial b_{B}}}-t_{B}=-\frac{\alpha}{\beta} e^{l}+\frac{1}{D_{B}}-t_{B},
$$

where $D_{B} \equiv-\frac{\frac{\partial n_{B}^{l}}{\partial b_{B}}}{n_{B}^{l}}$.

Therefore $b_{j}^{I I}, j=A, B$, decreases with $\alpha / \beta, e^{l}$, and $D_{j}$. However, $b_{j}^{I I}$ can be either positive or negative: university $j$ in principle can tax or subsidize its students according to the following relation

$$
b_{j}^{I I} \gtreqless 0 \quad \text { iff } \quad 1 / D_{j} \gtreqless \frac{\alpha}{\beta} e^{l}+t_{j} \quad \text { or iff } \quad t_{j} \lesseqgtr \theta_{j} \equiv 1 / D_{j}-\frac{\alpha}{\beta} e^{l} .
$$

Let us consider the case where the public transfer is sufficiently low, i.e. $t_{j}<\theta_{j}$. Then both universities will fix a positive tuition fee. Both universities have an incentive to fix a positive tuition fee to cover their expenditure on teaching. In university $A$, the level of the tuition fee is not so high as to discourage too many low ability students from enrolling; in university $B$, it is high enough to avoid to be attended by all low ability students (which would be the case covered by equilibrium I). 
Recall that in this equilibrium $\tau_{B}>R_{B}^{I I}$. Thus, in university $B$, part of the lump sum transfer is devoted to finance teaching and this helps raising teaching quality. Given that university $B$ has no high ability students its quality would otherwise be too low. Such positive effect on quality of the sum $\tau_{B}-R_{B}^{I I}$, however, is higher the lower is the number of students. For university $A$, instead, $\tau_{A}$ may be lower than $R_{A}^{I I}$, so that there may arise the need to attract students also to finance research.

Given (37) and in (38), the tuition fee and the per student transfer may be substitute, ${ }^{11}$ contrary to what happens in equilibrium I. In equilibrium II the tuition fee has an opportunity cost for university $j$, because of students' response. In equilibrium I, such opportunity cost does not exist as university $j$ does not gain anything by reducing $b_{j}$ (the derivative of the university objective function w.r.t. $b_{j}$ is always positive). In equilibrium II, instead, university $j$ directly gains by reducing $b_{j}$ because it can attract more low ability students.

\subsection{Equilibrium III}

At equilibrium III of the second stage, where $n_{A}=N$ and $n_{B}=0$, universities' objective functions are as follows

$$
W_{A}=N \alpha\left(\frac{N^{h}}{N} \Delta+e^{l}\right)+\beta\left[\left(t_{A}+b_{A}\right) N+\left(\tau_{A}-R_{A}\right)\right]+R_{A}^{\gamma_{A}},
$$

and

$$
W_{B}=R_{B}^{\gamma_{B}}
$$

Accordingly, the f.o.c for university $A$ w.r.t research expenditure is

$$
\partial W_{A} / \partial R_{A}=\gamma_{A} R_{A}^{\gamma_{A}-1}-\beta=0
$$

while w.r.t tuition fee we have

$$
\partial W_{A} / \partial b_{A}=\beta N>0
$$

so that university $A$ 's pay-off is monotonically increasing with $b_{A}$.

For university $B$, we obviously have that the pay-off is increasing in research expenditure as

$$
\partial W_{B} / \partial R_{B}=\gamma_{B} R_{B}^{\gamma_{B}^{-1}}>0
$$

\subsubsection{Optimal research expenditure}

For this equilibrium to exist, $R_{A}$ must be higher than $\tau_{A}$. As in equilibrium I, tuition fees are needed to finance research. From (39), the optimal level of research expenditure for university $A$, $R_{A}^{I I I}$, obtains as

$$
R_{A}^{I I I}=\left(\frac{\beta}{\gamma_{A}}\right)^{\frac{1}{\gamma_{A}-1}},
$$

\footnotetext{
${ }^{11}$ They are substitute if the semi-elasticity of low ability students w.r.t. the fee does not decrease with the perstudent transfer.
} 
and the optimal level of research obtains as

$$
r_{A}^{I I I}=\left(\frac{\beta}{\gamma_{A}}\right)^{\frac{\gamma_{A}}{\gamma_{A}-1}} .
$$

For university $B$, the optimal level of research expenditure, $R_{B}^{I I I}$, is simply as follows

$$
R_{B}^{I I I}=\tau_{B}
$$

and thus the optimal level of research obtains as

$$
r_{B}^{I I I}=\tau_{B}^{\gamma_{B}}
$$

In university $A$ where there are all the students, the level of expenditure in research is the same as that in equilibrium I. Again, $R_{A}^{I I I}$ depends only on technological parameters, and thus it is independent of the public lump sum transfer, i.e. $\frac{\partial R_{A}^{I I I}}{\partial \tau_{A}}=0$. In university $B$ only research is carried on, and its expenditure just equals the public lump sum transfer, i.e. $\frac{\partial R_{B}^{I I I}}{\partial \tau_{B}}=1$.

\subsubsection{Optimal per student tuition fee}

At equilibrium III, the government does not finance teaching at university $B$, i.e. $t_{B}=0$. Analogously to equilibrium I, given (40) and given that $U^{h}\left(q_{j}\right)>U^{l}\left(q_{j}\right) \forall q_{j}, j=A, B$, university $A$ will choose the value of the optimal tuition fee $b_{A}^{I I I}$ by solving the following equation:

$$
U^{l}\left(\alpha\left(e^{l}+\frac{\Delta N^{h}}{N}\right)+\beta\left(t_{A}+b_{A}^{I I I}+\frac{\tau_{A}-R_{A}^{I I I}}{N}\right)\right)-b_{A}^{I I I}=0 .
$$

Notice that this implies that

$$
U^{h}\left(\alpha\left(e^{l}+\frac{\Delta N^{h}}{N}\right)+\beta\left(t_{A}+b_{A}^{I I I}+\frac{\tau_{A}-R_{A}^{I I I}}{N}\right)\right)-b_{A}^{I I I}>0,
$$

i.e. high ability students enjoy a higher level of utility than low ability ones. ${ }^{12}$

As in equilibrium $\mathrm{I}, t_{A}$ and $b_{A}^{I I I}$ are complements, being the tuition fee with no opportunity cost. A higher level of $t_{A}$ in fact enables university $A$ to raise $b_{A}^{I I I}$ and, consequently, to raise teaching quality.

\section{$5 \quad$ A social comparison among equilibria}

In order to compare the three equilibria from a social point of view, we suppose that the government aims to obtain a high level of both total research and teaching quality. Let us start to compare equilibrium I and III, which are both specialized. In the former, university $A$ is an élite university attended only by high ability students, and university $B$ is only attended by low ability students. In the latter, university $A$ supplies both research and teaching, being attended by all students, while university $B$ is only a research institution.

\footnotetext{
${ }^{12}$ By only looking at equilibria where all potential students go to university we are implicitly assuming that the increase in university $A$ 's payoff from raising the tuition fee up to the level that would equate to zero the utility of high ability students is lower than the loss due to the fact that low ability students would not enrol.
} 
Proposition 4 For equal levels of tuition fees, $b^{I}=b_{A}^{I I I}$, teaching quality, $q^{I}=q_{A}^{I I I}$, and research, $r_{j}^{I}=r_{j}^{I I}, j=A, B$, public expenditure is lower in equilibrium I than in equilibrium III.

Proof. See the appendix

In terms of resource allocation, this proposition implies that equilibrium $\mathrm{I}$ is more efficient than equilibrium III. Then, as education policy, the government should choose the structure of grants corresponding to equilibrium I. Only if the government wants to induce a higher level of research

than $\sum_{j=A, B}\left(\frac{\beta}{\gamma_{j}}\right)^{\frac{\gamma_{j}}{\gamma_{j}-1}}$, the structure of grants should be modified in order to shift to equilibrium III.

We may then compare equilibrium I to equilibrium II, recalling that in the latter university $A$ is attended by both types of students while university $B$ is only attended by low ability students. We know that in equilibrium I research, and consequently research expenditure, is higher than in equilibrium II. Therefore, we compare the two equilibria in terms of equal levels of extra research resources, i.e. total public transfers net of expenditure devoted to research activity. In this respect, we state the following

Proposition 5 For equal levels of extra-research resources, average teaching quality is higher in equilibrium I than in equilibrium II.

Proof. See the appendix.

Proposition 5 means that at the same teaching cost, teaching quality is higher in the segregated state university system of equilibrium I than in the mixed state university system of equilibrium II.

According to our propositions, we may say that equilibrium I is more efficient than both equilibrium II and III. Clearly, the notion of efficiency we have in mind is referred to the assumed social objective of high teaching quality and research achievement at the lowest cost.

\section{Concluding remarks}

In this paper, we have analysed the impact of student mobility on the characteristics of two competing state universities. Assuming two types of students ('high ability' and 'low ability'), the composition of the population of students impacts on the quality of teaching. The latter is an argument of the individual utility function ('peer effect') as well as of the universities' objective functions. The level of research (which is linked to research expenditure by efficiency parameters) is the other argument of the universities' objective functions. Each university decides the level of its tuition fees and of its research expenditure. The government contributes to financing the universities with a lump sum transfer and a matching grant per student. The aim of the government is to promote a high level of research and teaching quality by making an efficient use of financial resources. As we adopt a partial equilibrium approach emphasizing only students' utility, we do not consider a welfarist objective function for the government. In other words, we consider research and teaching quality as merit goods, although their provision is constrained by budget concerns. 
By selecting locally stable equilibria, the analysis has ruled out some institutional settings in favour of some others. One of the main results is that high ability students always concentrate in the same university. Due to the existence of a positive peer effect, there cannot exist a stable equilibrium where high ability students divide between different universities. We have three types of equilibria. In equilibrium I, an élite institution is created with only high ability individuals (university $A$ ) while low ability students are segregated in a different institution (university $B$ ). In equilibrium II, all high ability and part of the low ability ones attend one university (university $A$ ) while the rest attends the other university (university $B$ ). In equilibrium III, all students are concentrated in one university (university $A$ ), while the other institution becomes a research center.

Equilibrium I stands out as the most efficient. When compared to equilibrium III, equilibrium I allows to reach the same teaching quality and research level at a lower public cost. When compared to equilibrium II, equilibrium I allows to attain a higher teaching quality at the same public extra research cost. In equilibrium I, the level of research expenditure is entirely explained by technological parameters of the research production function. Thus, research productivity is crucial in defining the level of public expenditure. A somewhat surprising result is that teaching quality is the same in both universities despite students' segregation. In order to have equilibrium I, the lump sum transfer must be lower than research expenditure. So research must be partly financed by tuition fee revenue and per student transfers. As far as tuition fees are concerned, these must be equal in both universities. However, the government tends to compensate the effect of low ability students in university $B$ because the per student transfer in this university is higher than in university $A$.

Only if the government wanted to reach a higher research level than the one embedded in equilibrium I, it should rely on equilibrium III where a pure research center can be created totally financed with a lump sum transfer. In the other university, now attended by all the students (both high and low ability) the lump sum transfer is lower than research expenditure. Here research expenditure is significatively financed by tuition fees.

In equilibrium II, the level of research is lower than in both equilibria I and III. In university $B$, attended only by low ability students, the lump sum transfer from the government must be greater than research expenditure. The residual part of these funds are devoted to finance teaching so as to raise teaching quality. In this case a relatively low number of students is sufficient because research is self sustaining. Part of the low ability students attend university $A$ where the lump sum transfer may be lower than research expenditure. This turns out in a lower average teaching quality in equilibrium II (for a given amount of public resources) than in equilibrium I.

\section{Appendix}

\section{Proof of Proposition 4.}

Consider that $r_{A}^{I I I}=r_{A}^{I}=\left(\frac{\beta}{\gamma_{A}}\right)^{\frac{\gamma_{A}}{\gamma_{A}^{-1}}}$. Let us fix $r_{B}^{I I I}=r_{B}^{I}=\left(\frac{\beta}{\gamma_{B}}\right)^{\frac{\gamma_{B}}{\gamma_{B}-1}}$, which results in research expenditure $R_{B}^{I I I}=\left(\frac{\beta}{\gamma_{B}}\right)^{\frac{1}{\gamma_{B}^{-1}}}$. We show that any level of $q^{I}=q_{A}^{I I I}$ can be obtained 
with the same level of tuition fee, but with a lower public expenditure in equilibrium I than in equilibrium III.

The government can fix the lump sum transfers as follows:

$$
\begin{array}{ll}
\tau_{A}^{I}=R_{A}^{I}-\epsilon^{I}, & \tau_{A}^{I I I}=R_{A}^{I I I}-\frac{\alpha}{\beta} \Delta N^{h}-\epsilon^{I I I}, \\
\tau_{B}^{I}=R_{B}^{I}-\epsilon^{I}, & \tau_{B}^{I I I}=R_{B}^{I I I},
\end{array}
$$

where $\epsilon^{I}=\epsilon^{I I I} \frac{N^{l}}{N}>0$, and can fix the per-student transfers as follows

$$
\begin{aligned}
t_{A}^{I I I} & =t_{B}^{I}, \\
t_{A}^{I} & =t_{B}^{I}-\frac{\alpha}{\beta} \Delta .
\end{aligned}
$$

Then, tuition fees and teaching qualities in equilibrium I and III are determined from (29)

$$
U^{l}\left(\alpha e^{l}+\beta\left(t_{B}^{I}+b^{I}-\frac{\epsilon^{I}}{N^{l}}\right)\right)-b^{I}=0,
$$

and from (43)

$$
U^{l}\left(\alpha\left(e^{l}+\frac{\Delta N^{h}}{N}\right)+\beta\left(t_{A}^{I I I}+b_{A}^{I I I}-\frac{\frac{\alpha}{\beta} \Delta N^{h}+\epsilon^{I I I}}{N}\right)\right)-b_{A}^{I I I}=0,
$$

respectively. This implies

$$
b^{I}=b_{A}^{I I I} \quad \text { and } \quad q^{I}=q_{A}^{I I I} .
$$

The cost for the government in equilibrium I and III are respectively equal to

$$
\begin{aligned}
C^{I} \equiv & \tau_{A}^{I}+\tau_{B}^{I}+t_{A}^{I} N^{h}+t_{B}^{I} N^{l}=R_{A}^{I}+R_{B}^{I}-2 \epsilon^{I}+t_{B}^{I} N^{l}+\left(t_{B}^{I}-\frac{\alpha}{\beta} \Delta\right) N^{h}= \\
& =R_{A}^{I}+R_{B}^{I}+t_{B}^{I} N-2 \epsilon^{I}-\frac{\alpha}{\beta} \Delta N^{h}
\end{aligned}
$$

and

$$
\begin{aligned}
C^{I I I} & \equiv \tau_{A}^{I I I}+\tau_{B}^{I I I}+t_{A}^{I I I} N=R_{A}^{I I I}+R_{B}^{I I I}-\frac{\alpha}{\beta} \Delta \frac{N^{h}}{N}-\epsilon^{I I I}+t_{A}^{I I I} N= \\
& =R_{A}^{I}+R_{B}^{I}+t_{B}^{I} N-\epsilon^{I} \frac{N}{N^{l}}-\frac{\alpha}{\beta} \Delta \frac{N^{h}}{N}
\end{aligned}
$$

Thus, $C^{I}<C^{I I I}$ as $\frac{N}{N^{l}} \leq 2$.

\section{Proof of Proposition 5.}

We show that the teaching quality in equilibrium I is higher than the maximum average teaching quality achievable in equilibrium II. Define the maximum average teaching quality achievable in equilibrium II, $\widehat{q}^{I I}$, as a weighted average of the maximum teaching quality in university $A, \widehat{q}_{A}^{I I}$, and in university $B, \widehat{q}_{B}^{I I}$, where

$$
\widehat{q}_{A}^{I I}=\alpha\left(e^{l}+\Delta \frac{N^{h}}{N^{h}+n_{A}^{l}}\right)+\beta\left(b_{A}^{I I}+t_{A}^{I I}+\frac{\alpha}{\beta} \Delta \frac{n_{A}^{l}}{N^{h}+n_{A}^{l}}-\delta_{A}^{I I}\right),
$$


and

$$
\widehat{q}_{B}^{I I}=\alpha e^{l}+\beta\left(b_{B}^{I I}+t_{B}^{I I}+\frac{\alpha}{\beta} \Delta-\delta_{B}^{I I}\right)
$$

with $\delta_{j}^{I I}, j=A, B$, arbitrarily small. Both $\widehat{q}_{A}^{I I}$ and $\widehat{q}_{B}^{I I}$ expressions are obtained by setting $\tau_{j}^{I I}-R_{j}^{I I}$ at the maximum amount compatible with the conditions underlying equilibrium II (see (16) and (17)). Consequently,

$$
\widehat{q}^{I I}=\alpha e^{l}+\alpha \Delta+\beta\left(\left(b_{A}^{I I}+t_{A}^{I I}\right) \frac{N^{h}+n_{A}^{l}}{N}+\left(b_{B}^{I I}+t_{B}^{I I}\right) \frac{n_{B}^{l}}{N}-\delta^{I I}\right),
$$

where $\delta^{I I}=\frac{N^{h}+n_{A}^{l}}{N} \delta_{A}^{I I}+\frac{n_{B}^{l}}{N} \delta_{B}^{I I}$. The cost for the government in equilibrium II is equal to

$$
\widehat{C}^{I I}=\frac{\alpha}{\beta} \Delta N^{l}+R_{B}^{I I}+R_{A}^{I I}-\delta^{I I} .
$$

So the extra-research financing is $\frac{\alpha}{\beta} \Delta N^{l}-\delta^{I I}$. If we consider the same level of extra research financing in equilibrium $I$, we obtain the following cost for the government

$$
\widehat{C}^{I}=\frac{\alpha}{\beta} \Delta N^{l}+R_{B}^{I}+R_{A}^{I}-\delta_{A}^{I}-\delta_{B}^{I}
$$

where $\frac{\delta_{A}^{I}}{N^{h}}=\frac{\delta_{B}^{I}}{N^{l}}$, in order to satisfy the equal quality condition $q_{A}^{I}=q_{B}^{I}=q^{I}$ (proposition 2), and $\delta_{A}^{I}+\delta_{B}^{I}=\delta^{I I}$. Given this cost, by setting $t_{B}^{I}=\frac{\alpha}{\beta} \Delta+t_{A}^{I}$, and

$$
t_{A}^{I}=\frac{t_{A}^{I I}\left(N^{h}+n_{A}^{l}\right)+t_{B}^{I I} n_{B}^{l}}{N}
$$

we obtain the following teaching quality level

$$
q^{I}=\alpha e^{l}+\alpha \Delta+\beta\left(\frac{t_{A}^{I I}\left(N^{h}+n_{A}^{l}\right)+t_{B}^{I I} n_{B}^{l}}{N}+b^{I}-\frac{\delta_{A}^{I}}{N^{h}}\right),
$$

which is higher than the maximum average teaching quality in equilibrium II, $\widehat{q}^{I I}$ in (45), because $b^{I} \geqslant b_{A}^{I I}>b_{B}^{I I}$. Indeed, given (29), $b^{I}$ is the maximum level of tuition fee corresponding to a non negative utility for low ability students, and it is clearly not lower than $b_{A}^{I I}$. Moreover, $b_{A}^{I I}>b_{B}^{I I}$ from proposition 3 .

\section{References}

[1] Aghion, P., Dewatripont, M., Hoxby, C., Mas-Colell, A., Sapir, A. (2010), The Governance and Performance of Universities: Evidence from Europe and the U.S., Economic Policy, 25, $61,7-59$.

[2] Bailey, M., M. Rom and M.Taylor (2004), State Competition in Higher Education: A Race to the Top, or a Race to the Bottom?, Economics of Governance, 5, 53-75.

[3] Bertola, G. and D. Checchi (2003), Education Financing and Student Achievement, Swiss Review of Education, 25, 431-54. 
[4] Boroah, V. (1994), Modelling Institutional Behaviour: A Microeconomic Analysis of Universities Management, Public Choice, 81, 101-124.

[5] Cohn, E., Cooper, S.T. (2004), Multi-product Cost Functions for Universities: Economies of Scale and Scope, in International Handbook on the Economics of Education, Johnes, G. and Johnes, J. (eds.), Cheltenham, Edward Elgar.

[6] De Fraja, G. Iossa, E (2002), Competition among Universities and the Emergence of the élite Institution, Bulletin of Economic Research, 54, 275-293.

[7] De Fraja, G., Valbonesi, P. (2008), The Design of the University System, CEPR Discussion Paper No. 7038.

[8] Del Rey, E. (2001), Teaching versus Research: A Model of State University Competition, Journal of Urban Economics, 49, 356-373.

[9] Epple, D., Romano, R.E. (1998), Competition Between Private and Public Schools, Vouchers, and Peer-Group Effects, American Economic Review, 88, 1, 33-61.

[10] Epple, D., Romano, R. (2008), Educational Vouchers and Cream Skimming, International Economic Review, 49(4), 1395-1435.

[11] Hindriks, J., Myles, G.D. (2006), Intermediate Public Economics, Cambridge, The MIT Press.

[12] Hübner M. (2009), Educational Federalism: Do Tuition Fees Improve Quality and the Number of Students?, CDSE Discussion paper No 67, University of Mannheim.

[13] Gautier, A., Wauthy, X. (2007), Teaching versus Research: A Multi-Tasking Approach to Multi-Department Universities, European Economic Review, 51, 273-295.

[14] Kemnitz, A. (2007), Funding, Competition and Quality in Higher Education, Journal of Institutional and Theoretical Economics, 63, 356-378.

[15] Johnes, G. (2007), Cherry-Picking in the Economics of Education Orchard: A Selective Survey of Recent Developments, in Economia del Capitale Umano. Istituzioni, Incentivi e Valutazione, Petretto, A. and Pignataro, G. (eds.), Milan, Franco Angeli.

[16] Oliveira, T. (2006), Tuition Fees and Admission Standards: How do Public and Private Universities Really Compete for Students, WP 06/6, Department of Economics, University of Leicester.

[17] Rothschild, M., White, L. J. (1995), The Analytics of the Pricing of Higher Education and Other Services in which the Customers are Inputs, Journal of Political Economy, 103, 573-586.

[18] Veugelers, R., Van Der Ploeg, F. (2008), Reforming European Universities: Scope for an Evidence-Based Process, CESifo WP No. 2298. 
[19] Wellish, D. (2000), The Theory of Public Finance in a Federal State, Cambridge, Cambridge University Press. 